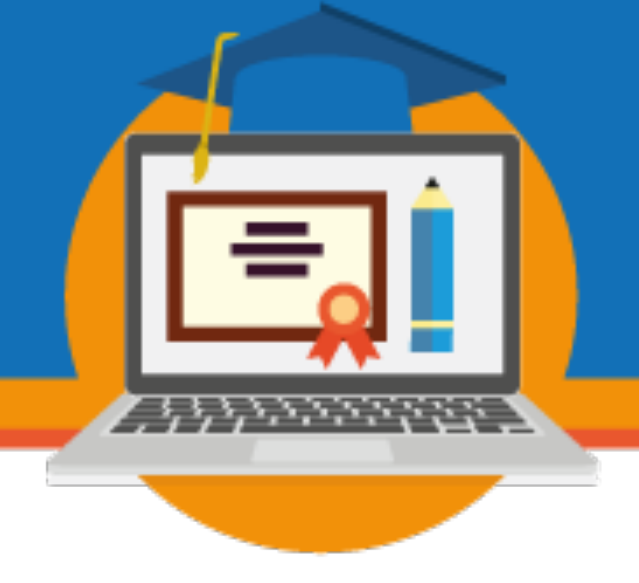

\title{
APRENDIZAGEM INVERTIDA NA EDUCAÇÃO FÍSICA: POSSIBILIDADES PARA A FORMAÇÃO DE PROFESSORES E MEDIAÇÕES PEDAGÓGICAS
}

\author{
Achilles Alves de Oliveira \\ Universidade Estadual de Goiás - UEG \\ achillesalves@gmail.com \\ Yara Fonseca de Oliveira e Silva \\ Universidade Estadual de Goiás - UEG \\ yarafonsecas09@gmail.com
}

Eixo 6 - Tecnologias e mediações pedagógicas

\begin{abstract}
Resumo:
A Aprendizagem Invertida é uma proposta emergente e apresenta novos caminhos para o processo de ensino de aprendizagem ativa e significativa. Seria a aprendizagem invertida uma possibilidade a ser contemplada na formação de professores e essa contribuiria com a prática e a mediação pedagógica no ambiente escolar? A partir da pesquisa bibliográfica os estudos trazem desafios e possibilidades para uma nova proposta pedagógica sendo possível inferir que a aprendizagem mais dinâmica e interativa, por meio de diferentes estratégias, pode trazer uma nova vivência para o futuro professor de educação física. A partir dos resultados parciais é possível afirmar que a aprendizagem invertida poderá auxiliar, se contemplada dentro do campo da formação de professores, a área da educação física escolar.
\end{abstract}

Palavras-chave: Aprendizagem Invertida. Educação Física. Prática e Mediação Pedagógica.

\section{Introdução}

Em pleno século XXI, refletir e discutir sobre as possibilidades para a prática e a mediação pedagógica de qualidade se faz importante, isso visto que os desafios não são poucos e diariamente o professor precisa lidar com uma gama de fatores que dificultam sua prática pedagógica efetiva. Há a ressignificação do seu papel, assumindo novas tarefas e atribuições, contemplando o estudante que tem a tecnologia como suporte para a aprendizagem e, no caso da educação física, o professor ainda precisa dar conta de uma diversidade de habilidades e 


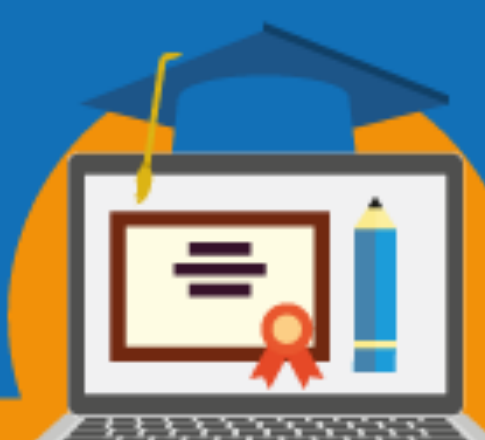

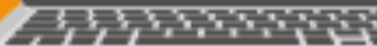

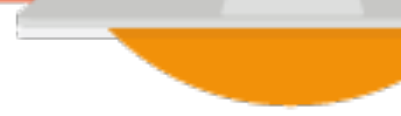

práticas corporais.

Nesse contexto, o professor de educação física nem sempre se vê preparado e confiante para lidar com essa complexidade em mediar tais experiências corporais no ambiente do jogo, da ludicidade e do movimento. Conflitos, dificuldades e situações de divergência são pontos recorrentes durante a aula de educação física.

Esse estudo parte da premissa que um ensino deve ser significativo, inclusivo e de qualidade, em um espaço rico para a aprendizagem e para o desenvolvimento do estudante. Pesquisas têm buscado na formação do professor alternativas para se contornar parte desses desafios. Muitas vezes, a melhoria na qualidade do ensino pode estar conectada com novas experiências durante a formação inicial e continuada daquele professor, local em que adquire conhecimentos e habilidades essenciais para sua prática e sua mediação pedagógica na escola.

É possível verificar algumas experiências que trazem novas formas de mediar o ensino, dentre elas, a Aprendizagem Invertida, do inglês, Flipped Learning. Como uma proposta emergente, ela apresenta novos caminhos para o processo de ensino a partir da aprendizagem ativa e significativa. Tal proposta já vem sendo utilizada em algumas instituições de educação básica e tem se expandido para ambientes universitários e profissionais.

Seria a aprendizagem invertida uma possibilidade a ser contemplada na formação de professores e essa contribuiria com a prática e a mediação pedagógica no ambiente escolar? Por ser uma proposta ainda pouco conhecida e difundida no Brasil, traz-se a necessidade de explorála, conhecer suas características e especificidades para buscar apresentar formas para sua aplicação.

$\mathrm{Na}$ educação física escolar, pouco ou quase nada existe na literatura sobre o tema, portanto, se justifica investigar esse tema para melhor compreender as possibilidades para sua prática pedagógica no meio escolar e, assim, repensar a melhoria da formação e qualificação do professor. Este estudo objetiva apresentar o conceito de aprendizagem invertida como uma possibilidade para a formação de professores da educação física escolar, profissionais que convivem com diversos desafios durante a prática e a mediação pedagógica.

Desta forma, a partir da pesquisa bibliográfica sobre o tema, busca-se aqui refletir sobre 


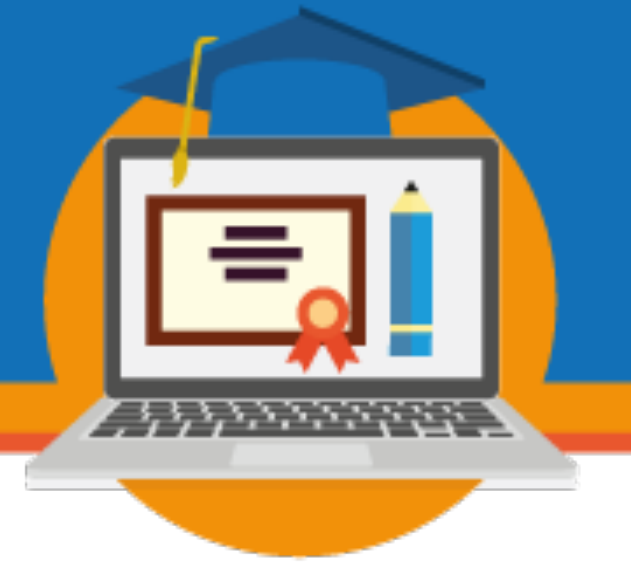

os resultados parciais de uma pesquisa' em andamento, obtidos em relação às possibilidades da utilização da aprendizagem invertida como parte da proposta pedagógica para a formação de professores.

Para isso, partiu-se de uma pesquisa exploratória, por meio de uma revisão de literatura que contemplou artigos e livros nacionais e internacionais. Partindo da compreensão das especificidades referente ao tema, neste estudo, apresenta-se parte da reflexão que tem sido realizada sobre a possibilidade da aprendizagem invertida ser contemplada na formação de professores de educação física escolar.

\section{Educação para o corpo, para o movimento e na diversidade}

A escola do século XXI traz uma complexidade que é influenciada direta e indiretamente por diversos fatores como sua região/localização, diversidade dos alunos, qualificação dos profissionais, recursos etc. Infelizmente, o modelo de ensino atual nem sempre colabora com o desenvolvimento de práticas que consideram esse contexto, importante para compreender e trazer novas propostas para a docência.

Segundo Bergmann e Sams (2012), o presente modelo de educação reflete o momento no qual este foi desenhado: a revolução industrial. Os autores afirmam que os estudantes são educados por meio de um ensino padronizado, em que todos sentam enfileirados, escutam um "expert" apresentando determinado conteúdo e, posteriormente, precisam lembrar tais conteúdos em uma prova. E quanto ao professor, sua mediação pedagógica se faz obsoleta por ser muitas vezes um transmissor de conhecimento. O que se pode incluir na proposta de formação de professores? E ao se falar da educação física, será que esta prática traz consigo os conhecimentos e habilidades de forma a compreender e intervir na complexidade do cotidiano escolar?

O corpo sente o mundo e sua cultura, recriando, transformando e também sofrendo

1 Pesquisa em fase de realização pelo primeiro autor deste trabalho, sendo vinculada ao Programa de PósGraduação Interdisciplinar em Educação, Linguagem e Tecnologias da Universidade Estadual de Goiás (PPG-IELTUEG).

III SEMINÁRIO DE EDUCAÇÃO A DISTÂNCIA

Diálogos sobre EaD e uso das TDIC na educação: regulamentação em tempos recentes 3 a 6 de novembro de 2020 - Brasília/DF - Online 
influência desta. "O corpo é a expressão-síntese da multidimensionalidade do ser humano" (CELANO, 1999, p. 43). É por meio do corpo, das suas percepções e sensações, que o indivíduo se expressa, se comunica, interage, sente, cria e recria as relações entre o mundo interior e o exterior, assim como defende Diniz (2003), de forma a reelaborar-se continuamente.

Criou-se uma educação voltada à supervalorização de aspectos cognitivos de forma a afastar a criança de experiências mais sensíveis, intuitivas e criativas. Dessa forma, é possível compreender a preocupação de Freire (1997), quando sugere que ao início do ano letivo o corpo também deveria ser matriculado na escola.

Muitas são as dificuldades dos professores em trabalhar com esse corpo que traz diferentes histórias, vivências, aptidões, dificuldades etc. Quando se fala num corpo com alguma deficiência, o estigma e o preconceito são reforçados em função desse corpo ser considerado inadequado, imperfeito, que não tem potencial de produção.

Ainda é complexo ao professor criar uma realidade que permita que toda criança tenha acesso a uma educação que lhe dê condições para desenvolver suas aptidões e sua individualidade em que, além disso, ela seja vista sob um olhar que a considera como alguém que "tem característica únicas, interesses, capacidades e necessidades de aprendizagem que lhe são próprias” (UNESCO, 1994).

É necessário que o indivíduo tenha sua história e experiências de vida respeitadas em sua singularidade, sentindo-se livre para vivenciar novas descobertas, para que possa se expressar. Cabe ao professor/mediador criar um espaço seguro e acolhedor, que promova um ambiente de liberdade para a expressão, que independente da sua condição física, psicológica ou intelectual, o aluno possa se sentir confiante para explorar ao máximo esse corpo. Mas será que os professores de educação física estão preparados para essa prática? "De modo geral, os professores não possuem estrutura afetiva para suportar a relação com corpos livres em movimento" (FREIRE, 1997, p. 170).

Percebe-se que esse atual modelo muitas vezes traz um formato de ensino que interrompe a aprendizagem do aluno ainda na base da pirâmide proposta pela Taxonomia de Bloom, em que o estudante acaba apenas desenvolvendo a capacidade de recordar ou 


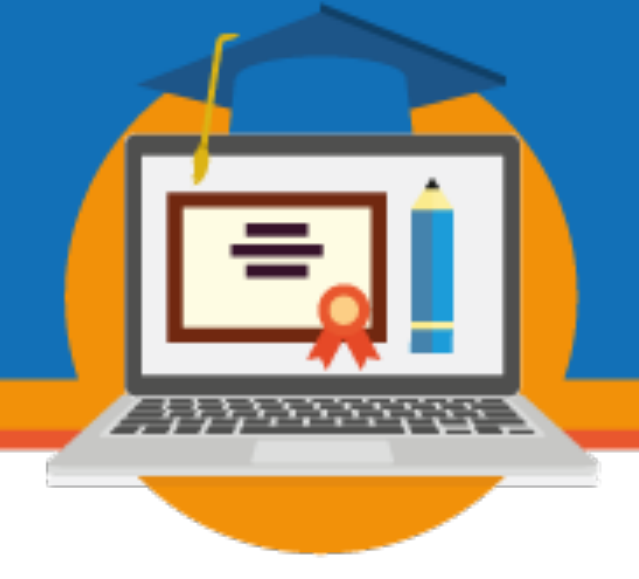

reconhecer determinado conhecimento (ADAMS, 2015). Ainda segundo a autora, apenas retomar este conhecimento não se torna evidência que o estudante possa realizar o próximo nível, este relacionado com a compreensão de dado conceito e, posteriormente, caminhando para sua aplicação, análise, síntese e avaliação.

Assim como na escola, na formação profissional não seria diferente. Em um modelo de ensino centrado no professor, torna-se fácil que as práticas e mediações desenvolvidas dentro da universidade ainda estejam um pouco distantes da realidade existente na escola. É possível que a formação profissional enfrente lacunas que reforcem uma existente dicotomia entre a teoria e a prática pedagógica, assim como trazem Mandú e Aguiar (2013).

Aprofundar nesses níveis subsequentes pode trazer experiências e habilidades que são essenciais para intervenção prática dentro da escola. Com isso, traz-se a possibilidade de contribuir para uma melhor qualificação dos futuros professores de educação física escolar ao lidarem com as necessidades e dificuldades relacionadas ao processo de ensino-aprendizagem dentro de seu contexto.

Alguns estudos trazem desafios e dificuldades que talvez poderiam ser contornados a partir de uma nova proposta pedagógica no decorrer da formação inicial e continuada do professor. Dentre eles, podemos citar Fernandes e Corrêa (2014) na educação infantil e Rodrigues e Schwantz (2016) na matemática. Por outro lado, novas metodologias e propostas pedagógicas vêm surgindo no intuito de aprimorar o ensino, possibilitando uma melhor qualificação dos futuros profissionais da educação, dentre elas, pode-se citar a Aprendizagem Invertida.

\section{Aprendizagem Invertida e a formação de professores}

A Aprendizagem Invertida é definida pela Flipped Learning Network - FLN como uma proposta pedagógica em que a instrução direta vai do ambiente de aprendizagem em grupo para um espaço de aprendizagem individual e, o espaço de aprendizagem em grupo, resultante de tal ação, é transformado em um ambiente de aprendizagem dinâmica e interativa em que o educador guia os estudantes à medida que aplicam conceitos e se engajam criativamente no 


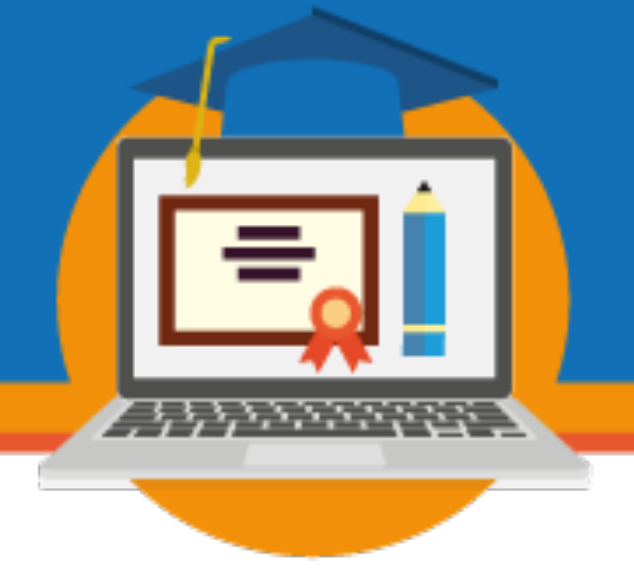

assunto (FLN, 2014). Portanto, a Aprendizagem Invertida é uma proposta voltada ao aprendizado do estudante, em que o educador considera a melhor forma de se utilizar o tempo de aula de maneira ativa.

A Aprendizagem Invertida extrapola o conceito de apenas uma técnica ou ferramenta pedagógica, ela trata de uma concepção ou filosofia de educação que abrange o design pedagógico de uma disciplina ou curso, além das práticas educativas desenvolvidas e do engajamento profissional do professor (TALBERT, 2017). A Aprendizagem Invertida se baseia principalmente em uma reorganização do formato no qual se é pensado a prática pedagógica, seja ela na escola ou no contexto universitário. Assim, ela pode ser definida como:

[...] uma abordagem pedagógica em que o primeiro contato com novos conceitos se desloca do ambiente de aprendizagem em grupo para o ambiente de aprendizagem individual, em forma de atividade estruturada. E, como resultado, o espaço em grupo é transformado em um ambiente de aprendizagem dinâmico e interativo no qual o educador guia os estudantes na medida em que aplicam conceitos e se envolvem criativamente no conteúdo da disciplina. (TALBERT, 2017, 1. 765, tradução nossa).

Não existe uma única estratégia que sirva e funcione em todas as salas de aula, para todos os professores e para cada aluno (BERGMANN; SAMS, 2014). A aprendizagem invertida possibilita que os professores utilizem diferentes metodologias de forma a focar em como abordar diversos estilos de aprendizagem durante a aula. A partir da inversão do que normalmente ocorre, os alunos têm acesso a um conteúdo prévio antes da aula. Isso se dá por meio de vídeos, apresentações, animações, infográficos, textos, questionários etc. Após essa fase, o professor atua como um guia, buscando investir mais tempo da aula em tarefas que requerem um maior nível de complexidade, por meio de um espaço em que estudantes estão explorando, aplicando, criando e resolvendo problemas (NEDERVELD; BERGE, 2015).

Dessa forma, a função do professor é, na realidade, ajudar os estudantes e não apenas entregar informações. Seu papel passa a ser como um coach da aprendizagem, em que investe seu tempo em conversas com os alunos, reflexões, respostas a questionamentos, trabalhos em pequenos grupos e trabalha de maneira a guiar para a aprendizagem de cada estudante (BERGMANN; SAMS, 2012). Rotellar e Cain (2016) apresentam que, a partir do momento em que o professor não é estritamente um provedor de conteúdo, ele pode agregar mais significado

\section{SEMINÁRIO DE EDUCAÇÃO A DISTÂNCIA}

Diálogos sobre EaD e uso das TDIC na educação: regulamentação em tempos recentes 3 a 6 de novembro de 2020 - Brasília/DF - Online 


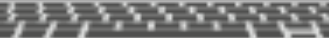

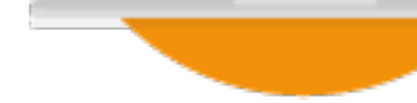

à experiência de sala de aula, visto que pode auxiliar e ensinar os estudantes a como raciocinar por meio de problemas e aplicar informações em questões da vida cotidiana. Esse pode ser um grande ponto a ser desenvolvido, principalmente ao abordar questões do dia-a-dia escolar durante a formação de professores.

Conforme abordado por Valente (2014), o aluno passa a ter uma postura mais participativa por meio da resolução de problemas, desenvolvimento de projetos, assim criando oportunidades para a construção do conhecimento. Autores como Bergmann e Sams (2012) trazem sua experiência de que as aulas passaram a ser um espaço para atividades significativas para a aprendizagem.

Essas propostas colocam o estudante em contato com uma aprendizagem mais significativa que, com um maior aprofundamento, atinge níveis superiores na Taxonomia de Bloom. Para isso, Valente (2014) aponta que diversas estratégias vêm sendo utilizadas visando promover uma aprendizagem ativa, baseada em pesquisas, jogos, metodologias como a Aprendizagem Baseada em Problemas (ABP), Aprendizagem Baseada em Problemas e por Projetos (ABPP), entre outras.

A partir dessa compreensão sobre Aprendizagem Invertida, é possível pensá-la implementada na complexa tarefa de formação de professores, para que se tenha uma mediação pedagógica com metodologias e ferramentas que desenvolvam conhecimentos e habilidades de forma a auxiliá-los no trabalho dentro da escola. No contexto da educação física, isso pode se dar de maneira a abarcar a complexidade existente nessa disciplina, considerando questões como inclusão, corporeidade e ludicidade.

Por meio de diversas ferramentas tecnológicas, o professor tem a possibilidade de criar e utilizar diferentes mídias para abordar o conteúdo e disponibilizá-lo antes da "aula". Dessa forma, diferentes estilos de aprendizagem podem ser abarcados, atuando de maneira mais inclusiva e respeitosa durante todo processo de aprendizagem. $\mathrm{O}$ estudante tem diferentes mídias com uma variedade de linguagens, seja por meio de vídeos, infográficos, animações, textos, quizzes, entre outros. Isso possibilita que o mesmo veja, pause, retome e reveja cada um deles de forma a compreender e se aprofundar nos conceitos chave antes de ir para o ambiente 


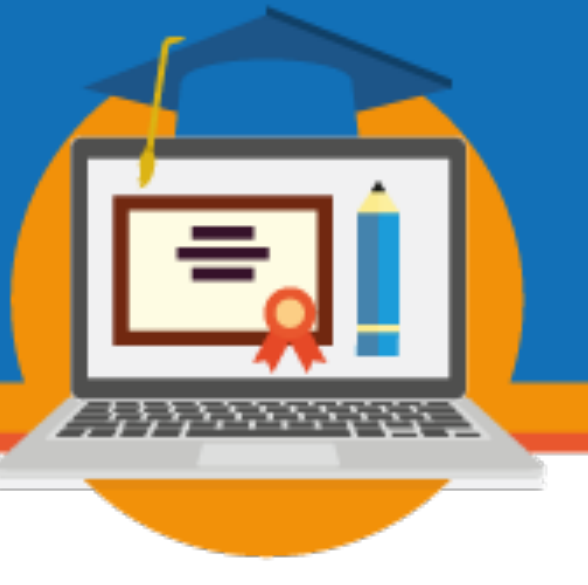

de aprendizagem coletiva em sala de aula.

Esse conteúdo, previamente disponibilizado, faz com que seja viável que o professor crie novas estratégias no momento de sala, tornando possível que o aluno aplique, analise, avalie e crie conceitos por meio das metodologias ativas. No caso da formação do professor de educação física, pensa-se que esse ambiente em sala (ou fora dela) seja um espaço para abordar a complexidade da corporeidade, ludicidade e inclusão por meio de ações que tornem a aprendizagem mais profunda e significativa.

Com um bom entendimento sobre a aprendizagem invertida, é possível inferir que, uma aprendizagem mais dinâmica e interativa, por meio de diferentes estratégias, pode trazer uma nova vivência para o futuro professor de educação física. Ter acesso a conteúdos prévios por meio de diversas linguagens e tecnologias facilita a criação de um espaço para se explorar, aplicar, criar e resolver problemas e questionamentos do cotidiano escolar. Isso pode se dar por meio de reflexões, atividades em grupo, discussões e projetos traçando um caminho para aproximar o professor com as reais demandas, necessidades e dificuldades do contexto escolar. Pois, ter um espaço para refletir por meio de problemas do cotidiano da escola pode preparar melhor esse profissional para o momento no qual estiver em sua real prática pedagógica.

\section{Considerações Finais}

A partir de uma realidade escolar que traz diariamente desafios aos professores e com especificidades no campo da educação física, propostas como a Aprendizagem Invertida podem trazer importantes possibilidades e sugestões para prática e mediação pedagógica na formação de professores de educação física. Por meio do uso das tecnologias e práticas que promovem reflexões, projetos e problemas, busca-se uma aproximação do professor em formação com a realidade e desafios que serão encontrados no contexto educacional.

Devido a sua possibilidade de maior interação com os estudantes e a existência de um contexto que possa promover um conhecimento mais aprofundado e diferenciado, se faz relevante buscar compreender melhor a Aprendizagem Invertida que ainda é pouco conhecida 


\section{$\equiv$ ii

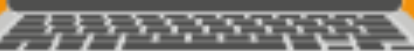

e difundida em pesquisas no Brasil. A partir desses resultados parciais é possível afirmar que a Aprendizagem Invertida pode ser um caminho para auxiliar, se contemplada dentro do campo da formação de professores, a área da educação física escolar.

\section{Referências}

ADAMS, N. Bloom's Taxonomy of Cognitive Learning Objectives. Journal of the Medical Library Association: JMLA 103.3 (2015): 152-153. PMC.

BERGMANN, J.; SAMS, A. Flip Your Classroom: Reach Every Student in Every Class Every Day. Eugene, Or: International Society for Technology in Education, 2012.

BERGMANN, J.; SAMS, A. Flipped learning: gateway to student engagement. Estados Unidos da América: International Society for Technology in Education - ISTE, 2014.

CELANO, S. Corpo e mente na educação: uma saída de emergência. Petrópolis, RJ: Vozes, 1999.

DINIZ, S. V . Corpo e expressão: uma experiência de arte na educação especial. Site \& Insight, Brasília - DF, ano 1, n 1, p. 145-158, 2003.

FERNANDES, M.; CORRÊA, C. Formação docente na educação infantil: desafios contemporâneos para a formação permante. Zero-a-Seis, Florianópolis, v. 16, n. 30, p. 275 289, ago. 2014.

FLN. The four pillars of F-L-I-P. Flipped Learning Network, 2014. Disponível em: https://flippedlearning.org/definition-of-flipped-learning/ Acesso em: 1 mai. 2018.

FREIRE, J. Educação de Corpo Inteiro: teoria e prática da Educação Física. São Paulo: Scipione, 1997.

MANDÚ, T. M. C., AGUIAR, M. C. C. A formação inicial no curso de pedagogia: concepções, caminhos e perspectivas dos estudantes. ETD - Educação Temática Digital, v. 15, n.3, p. 560- 


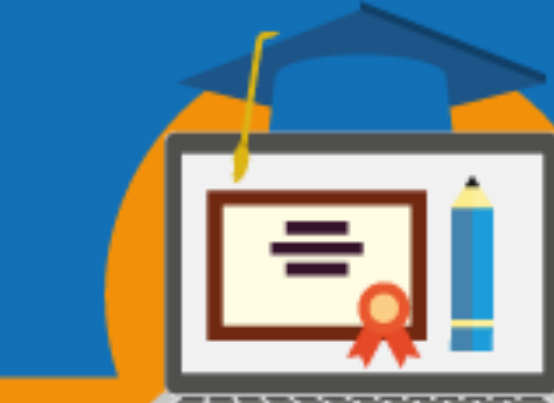

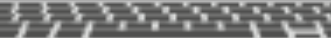

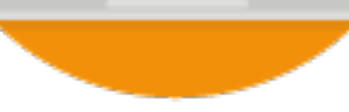

577

2013.

Disponível

em:

https://periodicos.sbu.unicamp.br/ojs/index.php/etd/article/view/1273 Acesso em 15 mai. 2018. https://doi.org/10.20396/etd.v15i3.1273

NEDERVELD, A.; BERGE, Z. Flipped Learning in the workplace. Journal of Workplace Learning, vol. 27, n. 2, p. 162 - 172, 2015. Disponível em: https://www.emeraldinsight.com/doi/pdfplus/10.1108/JWL-06-2014-0044. Acesso em: 17 jun. 18.

RODRIGUES, C. G.; SCHWANTZ, J. W. Buracos Negros na Formação Inicial de Professores de Matemática. Bolema, Rio Claro , v. 30, n. 56, p. 939-953, Dez. 2016 . Disponível em: http://www.scielo.br/scielo.php?script=sci arttext\&pid=S0103636X2016000300939\&lng=en\&nrm=iso. Acesso em 10 Ago. 2018.

TALBERT, R. Flipped learning: a guide for higher education faculty. Sterling, Virginia: Stylus Publishing, 2017.

UNESCO. The salamanca statement and framework for action on special needs education. Spain: UNESCO/Ministry of Education and Science, 1994. Disponível em: http://www.unesco.org/education/pdf/SALAMA_E.PDF. Acesso em: 10 mar. 2018.

VALENTE, J. A. Blended learning e as mudanças no ensino superior: a proposta da sala de aula invertida. Educar em Revista, Edição Especial, n. 4, p. 79-97, 2014. http://dx.doi.org/10.1590/0104-4060.38645 Acesso em: 10 abr. 2018. 